\title{
CLOUD BUSINESS INTELLIGENCE FOR SMES CONSORTIUM
}

\author{
Katarzyna ROSTEK*, Michał WIŚNIEWSKI**, Agnieszka KUCHARSKA*** \\ Faculty of Management \\ Warsaw University of Technology, Warsaw, Poland \\ *e-mail: k.rostek@wz.pw.edu.pl \\ **e-mail: m.wisniewski@wz.pw.edu.pl \\ ***e-mail: a.kucharska@wz.pw.edu.pl
}

\begin{abstract}
Business Intelligence technology for over 20 years is the market leader in analytical processing of data. As numerous market researches demonstrate Business Intelligence has substantial affect on global competitiveness of enterprises and on the stability of their position in the market, which is particularly important in times of economic downturn. Although main users of this technology are large companies and corporations, software vendors are still looking for solutions that are also available for the SME (Small and Middle Enterprises) sector and non-profit enterprises. One option available recently is possibility to use Cloud Computing environment. The article considers the opportunities and risks posed by the organization of Cloud Business Intelligence system on the example of using it in SME sector.
\end{abstract}

Keywords: Business Intelligence technology, Cloud Computing framework, Cloud Business Intelligence concept, SMEs, opportunities and limitations.

\section{1}

Introduction

The characteristic feature and the determinant of Business Intelligence (BI) effectiveness is the degree of its integration at the level of concept, organization and functioning ([2], [3]). This integration is hindered by locational, organizational and functional dispersion of data sources and system users. In the consideration case of the SME sector there is also the problem of having to take advantage of the high level of support in the design, construction as well as maintenance of the BI system. With the need to ensure high effectiveness and efficiency of its use. Due to the complexity of BI and the need of finding a solution ensuring optimum of the integration in distributed organization structure, it seems reasonable to propose architectural solutions based on Cloud Computing (CC) framework.

If it treats $\mathrm{CC}$ as the development of earlier former and concepts of services such as: grid computing, utility computing, distributed computing, visualization, and above all SaaS and outsourcing, that attempt to integrate these solutions with $\mathrm{BI}$ is being developed for several years in researches papers (e.g. [2], [8], [11] and [32]). All of them are carried out for long time with varying degrees of success, but each of them should be regarded as fragmented in comparison to all the needs of the SME sector. Therefore this article presents the concept of integration BI solution in CC environment, dedicated for SMEs enterprises. The purpose of the construction of such a solution is making availa- ble BI solutions to SMEs sector, taking into account full package of economic, organizational and functional constraints in the implementation and use of them. This objective can be expressed by the research question to which the answer will be sought:

How the restrictions in implementing of Business Intelligence can be eased or eliminated through using Cloud Computing technology?

The answers to the above question was subordinated to the structure of the presented article. In section 2 of the article possibilities and limitations of BI technologies are discussed. Properties and specifics of CC technology are presented in section 3. Varieties variants of the integration of BI with CC concept are described in section 4. In section 5 the proposal for Cloud Business Intelligence (CBI) implementation concept for SMEs are placed. The article ends with summaries and conclusions in section 6 .

\section{Specificities, possibilities and limitations of Business Intelligence technology}

Business intelligence is gathering, managing, analyzing, and sharing of information in order to gain insights that can be used to make better decisions [14]. The most important purpose of BI is to provide business managers and analyzers the instruments required conducting analysis [30]. 


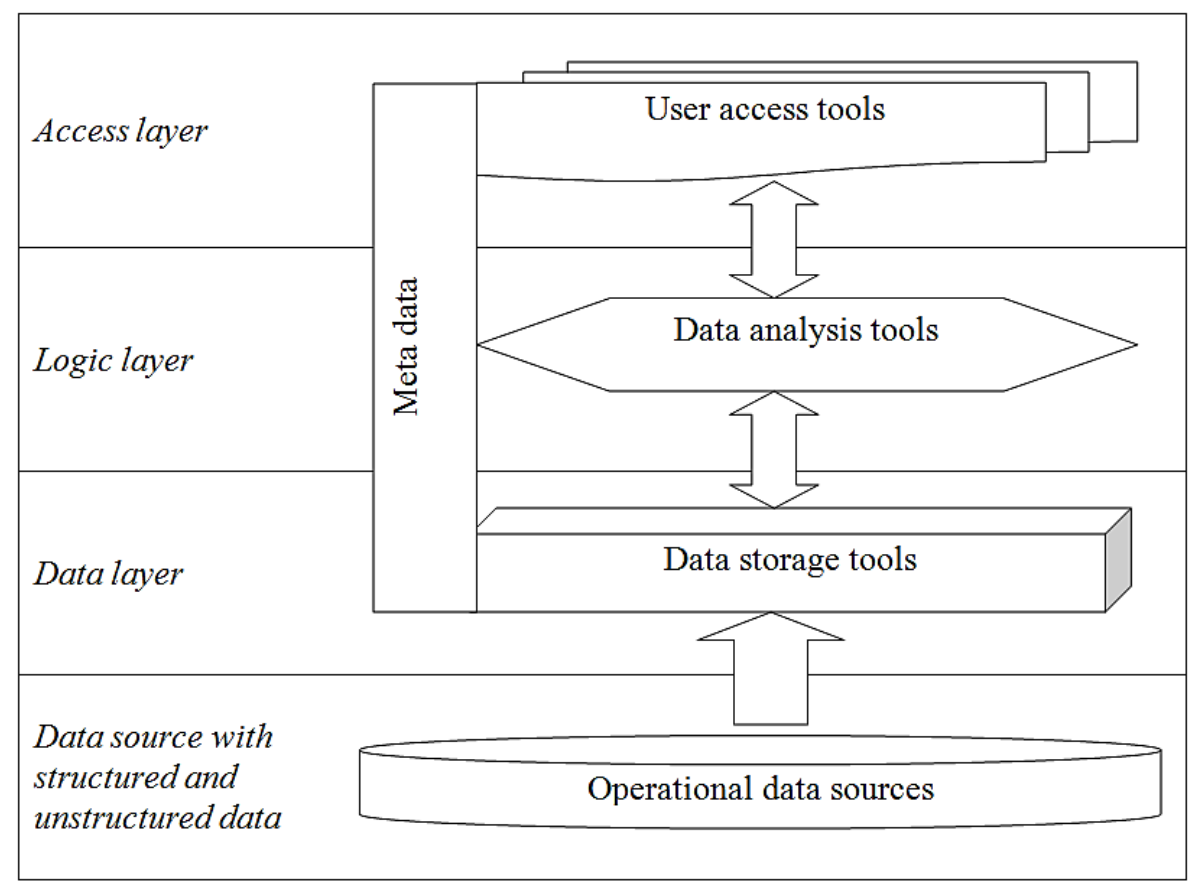

Figure 1. Conceptual three-layer BI architecture (source: based on [2])

It can extract and organize available information to help users to make timely and accuracy decisions to promote management, marketing and company development by fully using present business information and modern techniques [35]. Cui et al. [9] consider BI as way and technique of developing business performance by supplying influential supports for managerial decision maker to let them to have liable information at hand. BI tools are viewed as technology that facilitates the effectiveness of business function by giving an enhanced value to the enterprise information and therefore the way this information is used. BI can also improve financial performance and service, it allows to sustain the competing merit and to bring more economics benefits for company through analyzing and holding new opportunities and finding potential threats.

These all is done through interactive access to existing and historical information, circumstances, and executions, which all supply perception in the organization and makes capable intelligent decisions. BI can be served as architecture, tool, technology, or system that collects, stores, and analyses data by analytical tools, facilities reporting, querying and delivers information that eventually lets organizations to enhance decisionmaking [30]. The BI systems contribute to enhancement and precision of information flows, and know- ledge management and they make capable organizations to ([20], [25]):

- pursue profitability of their goods sold,

- analyze costs,

- monitor incorporated environments,

- detect business anomalies and frauds.

The basic architecture of BI contains three layers (see Fig. 1): data, logic and access. Data layer is cleaning and transforming useful data, extracted from many different data sources. Then, after ensuring its accuracy, loading them into data warehouse, data mart or data store. Logic layer is analyzing data by suitable queries and analysis tools, data mining tools, OLAP tools, etc. Finally, access layer presents the results of logic layer for supporting management decisions. It is realized with graphical user interface, analytical application or web portal.

According to IDC $^{1}$ researches the market of Business Intelligence is now the fastest growing IT sector and one of the few that have experienced growth in own value during crisis years.

\footnotetext{
${ }^{1}$ IDC (International Data Corporation) - one of the biggest companies involved in researches of the global ICT market. It deals with the preparation of sectoral researches, is a strategic advisor to ICT projects. The main its goal is to provide analysis on current and future development trends in individual sectors of the ICT market.
} 
According to IDG $^{2}$ and SAS Insitute ${ }^{3}$ experiences [36] it happens because enterprises see in this IT tools category a chance to gain competitive advantage $(80 \%$ of surveyed companies) and overcome the effects of economic slowdown (70\% of surveyed companies).

Mentioned SAS research was conducted in 2009 among 80-plus medium and large Polish companies. It showed that the most important effects of the Business Intelligence system implementation are [36]: higher quality and better availability of management information (62\% of respondents), the possibility of optimization and efficiency improvement of business processes $(60 \%$ of respondents), a support in reasonable reduction of operating costs (44\%), an increase in management efficiency (40\% of respondents), an increase of revenue ( $20 \%$ of respondents), an improved relationships with customers $(16 \%$ of respondents), an increased financial transparency within the enterprise (10\%). Surveyed entrepreneurs are using or have used Business Intelligence tools in the management of [36]: finance (56\%), strategy (38\%), customer relationship (38\%), supply chain (16\% of respondents), production (16\% respondents), marketing (12\% of respondents), human resources $(8 \%$ of respondents).

Although the survey was conducted among medium and large enterprises, providers of Business Intelligence solutions said that for the same reasons the SME sector enterprises buy those solutions more and more often $[10$, p. 16-26]. This was possible because more and more software producers begin to see the needs of SMEs, now their products are more financially available for this sector. However, as shown in author's survey results conducted among 150 dental clinics of the SME sector, the most important restrictions of the use of IT tools in supporting decision-making are [28]:

- lack of technical knowledge in the field of IT solutions decision-making support,

- lack of trained personnel, to whom implementation and maintenance of such solution could be addressed,

\footnotetext{
${ }^{2}$ IDG (International Data Group) - The international company dedicated to the provision of multimedia and marketing services, organization of conferences and meetings, scientific publishing, market research, consultancy of design and implementation and propagation of knowledge about modern IT technologies.

${ }^{3}$ SAS Institute - international IT corporation classified as Business Intelligence market leaders.
}

- limited knowledge of business management (management is mostly based on intuition and own experiences),

- limited financial resources which could be used in this type of investment,

- limited and often insufficient for multidimensional analysis the number of collected operational data resources.

Taking into account those limitations will be sought the such organization of BI system that provides the possibility of its implementation in the identified group of SMEs.

\section{Characteristics of Cloud Computing technology}

$\mathrm{CC}$ is a style of computing where massively scalable IT-related capabilities are provided "as a service" using Internet technologies to connect multiple external customers [26]. The name "cloud" is an acronym of: "Common, Location-independent, Online Utility that is available on Demand" [7].

$\mathrm{CC}$ refers to both - applications delivered as services over the Internet and the hardware and systems software that provide those services. It is emerging model of computing where hardware in large data centers can be dynamically provisioned, configured, and reconfigured to deliver services in scalable manner [15]. Summarizing the cloud model presents three new dimensions for computing [1, p. 1]:

- the infinite computing resources available on demand, thereby eliminating the need for cloud computing users to plan far ahead for provisioning.

- the elimination of up-front commitment by cloud users allowing to start from small and next increase hardware resources only when there is an increase in their needs.

- the ability to pay for use of computing resources on a short-term basis as needed (e.g., processors by the hour and storage by the day) and release them as needed, thereby rewarding conservation by letting machines and storage go when they are no longer useful. 


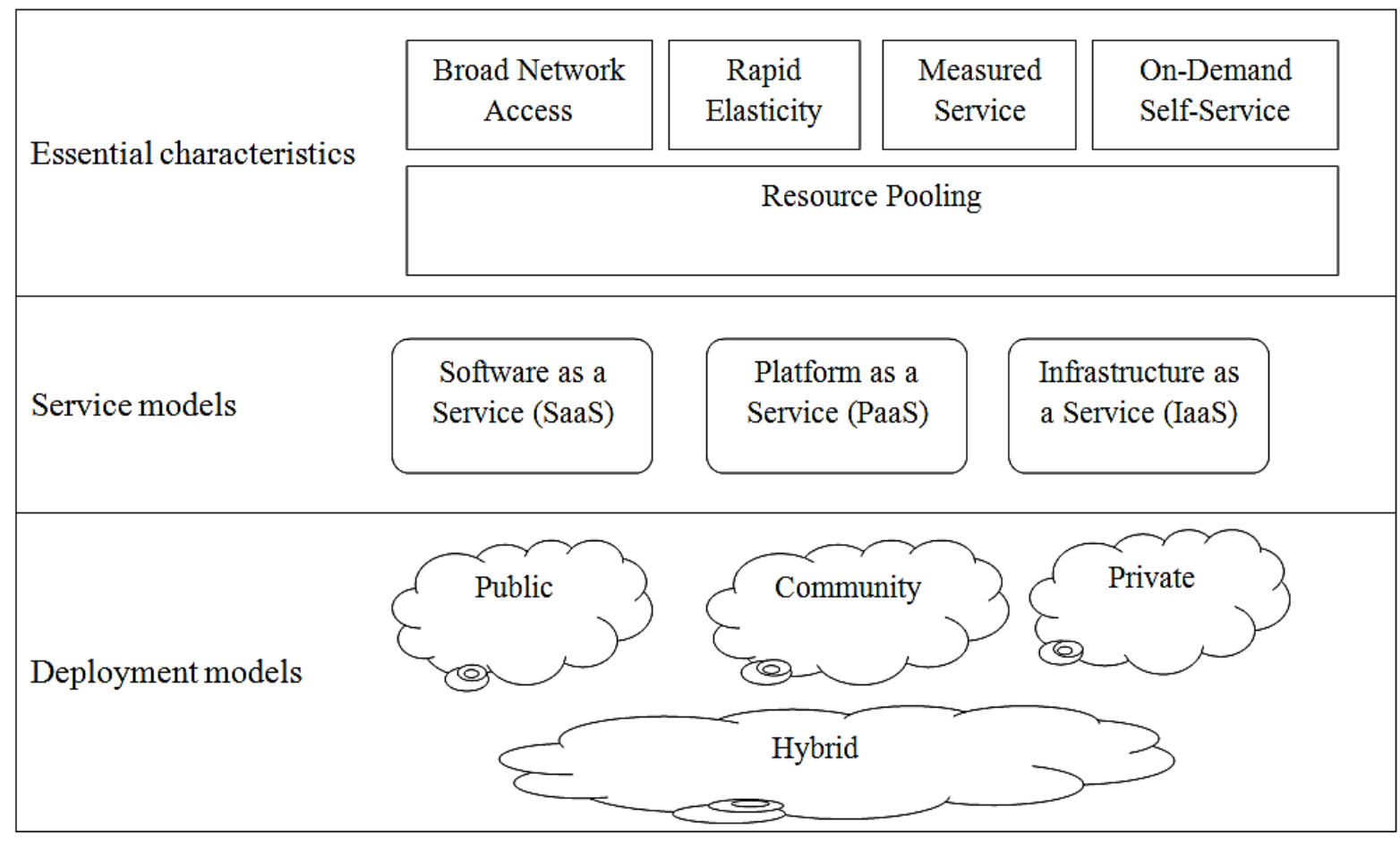

Figure 2. Visual model of NIST of Cloud Computing definition (source: based on [4])

The cloud model is composed of five essential characteristics, three service models, and four deployment models (see Fig. 2).

These five characteristics include [4]:

- broad network access - all computing resources are available over the network (e.g. internet) and accessed through standard mechanisms that promote use by heterogeneous thin or thick client platforms (e.g., mobile phones, laptops, and personal digital assistants),

- rapid elasticity - capabilities can be rapidly, in some cases automatically, and elastically provisioned; for consumers these capabilities are unlimited and can be purchased in any quantity at any time,

- measured service - cloud systems automatically control and optimize resource use by leveraging a metering capabilities at some level of abstraction appropriate to the type of service (e.g., storage, processing, bandwidth, and active user accounts); resource usage can be monitored, controlled, and reported providing transparency for both the provider and consumer of the utilized service,

- on-demand self-service - clients can ourselves control computing capabilities, such as server time (CPU time) and network storage, and as needed au- tomatically change them (conveniently by self serve method) without requiring human interaction with each service's provider,

- resource pooling - the cloud service provider's computing resources are pooled to serve multiple consumers using a multi-tenant model, with different physical and virtual resources dynamically assigned and reassigned according to consumer demand.

Three service models contain [4]:

- Software as a Service (SaaS) - the consumers use the provider's software applications, running on a cloud infrastructure,

- Platform as a Service (PaaS) - the consumers have access to the cloud infrastructure using programming languages and tools supported by the provider,

- Infrastructure as a Service (IaaS) - the consumers get provision to processing, storage, networks, and other fundamental computing resources where the consumer is able to deploy and run arbitrary software, which can include operating systems and applications.

The type of CC model is related to division of level of management and responsibility between user vs. service provider (see Table 1). 
Table 1. Division of management and responsibility between user vs. service provider (source: based on [13], p. 19)

\begin{tabular}{|c|c|c|c|}
\hline $\begin{array}{c}\text { Self-managed/ } \\
\text { self-owned }\end{array}$ & IAAS & PAAS & SAAS \\
\hline Application & Organization has control & $\begin{array}{c}\text { Organization shares con- } \\
\text { trol with vendor }\end{array}$ & Vendor has control \\
\hline Virtual machine & $\begin{array}{c}\text { Organization shares control } \\
\text { with vendor }\end{array}$ & $\begin{array}{c}\text { Organization shares con- } \\
\text { trol with vendor }\end{array}$ & Vendor has control \\
\hline Server & Vendor has control & Vendor has control & Vendor has control \\
\hline Storage & Vendor has control & Vendor has control & Vendor has control \\
\hline
\end{tabular}

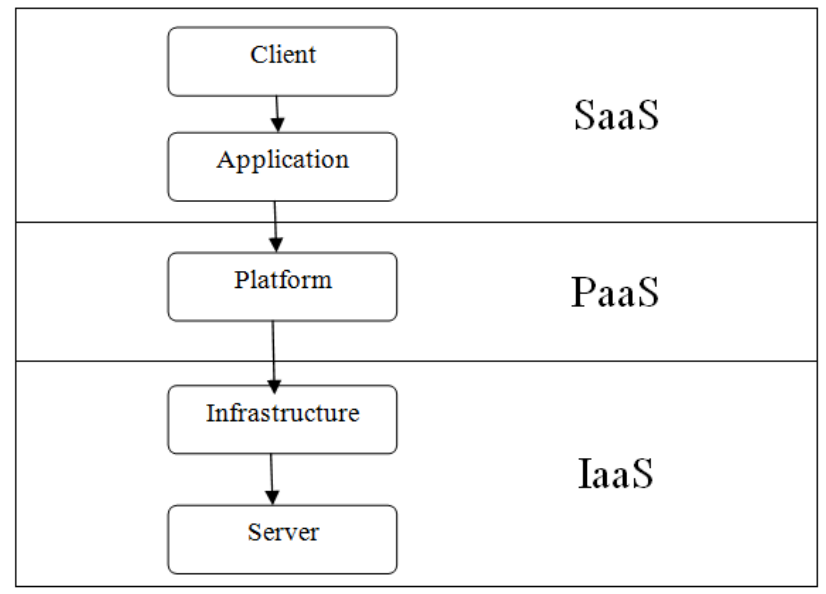

Figure 3. Relations between architecture layers and service models in $\mathrm{CC}$ (source: based on [24])

These three types of models handle five layers of cloud computing architecture (see Fig. 3):

- server layer - the base layer comprised of servers, hardware and software, present in different locations interconnected with high speed network connections,

- infrastructure layer - the layer which contains infrastructure as a service, provided by the service provider in the form of virtual machines or operating systems,

- platform layer - such capabilities as developing and testing applications without investing into additional hardware or software, services for team collaboration, web services integration, operated online desktop-like environment, etc.,

- application layer - access to applications without installing and updating any software on the computers locally,
- client layer - the final layer comprised of both hardware and software required in the cloud network for correct functioning.

Finally, the four deployment models are [4]:

- private cloud - the cloud infrastructure operates solely for an organization,

- community cloud - the cloud infrastructure is shared by several organizations and supports a specific community of these organizations with common mission, strategic objective, security policy, etc.,

- public cloud - the cloud infrastructure is available to the general public or a large industry group and is owned by an organization selling cloud services,

- hybrid cloud - the cloud infrastructure is a composition of two or more clouds (private, community, or public) that remain unique entities but are bound together by standardized or proprietary technology that enables data and application portability (e.g., cloud bursting for load-balancing between clouds). 


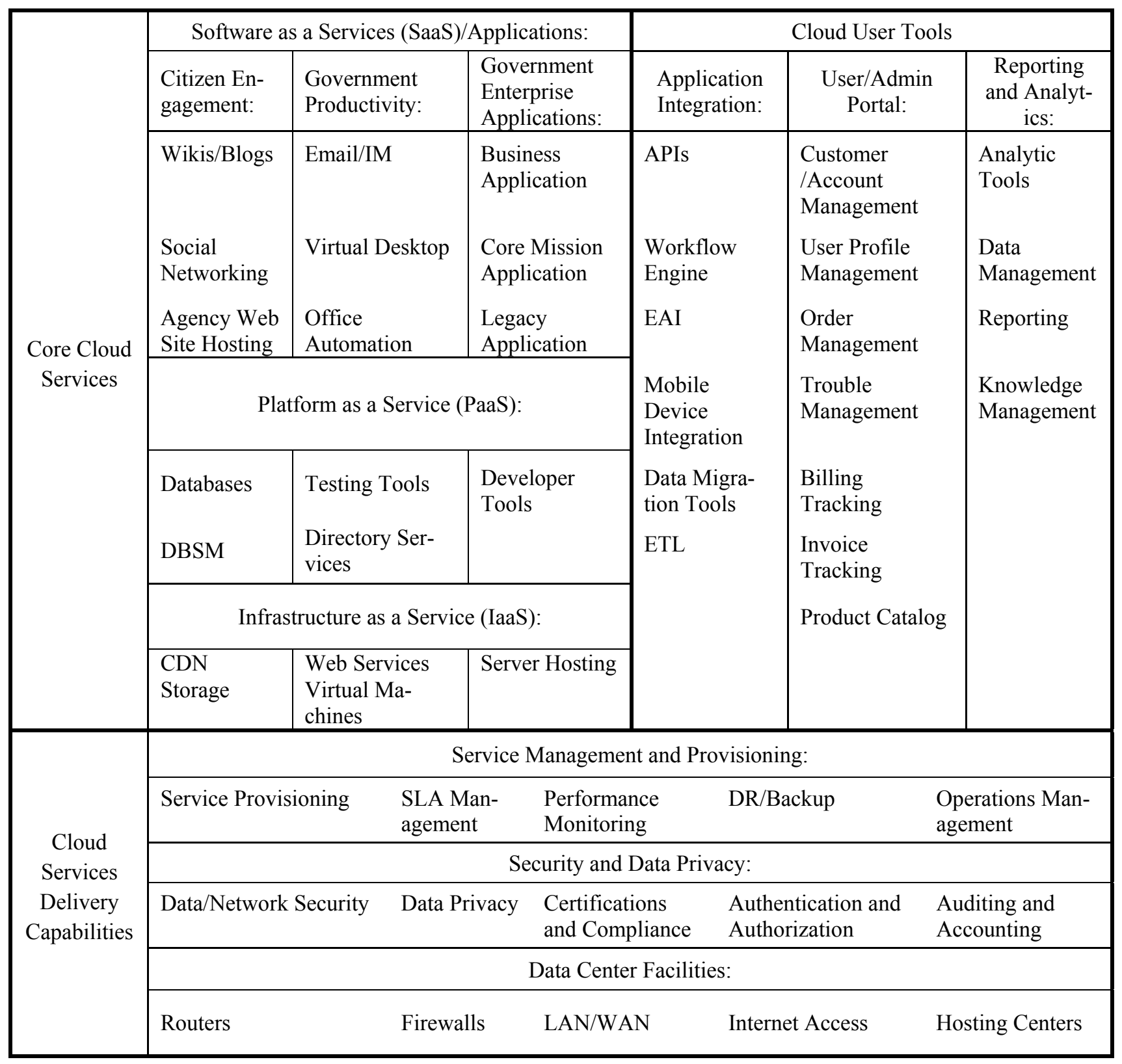

Figure 4. Practical example of CC technical framework (source: [12, p. 4])

All above elements form the framework of CC solution. The example of this framework is illustrated below at the Fig. 4. Practical example of CC technical framework (Fig. 4) provides a high-level overview of the key functional components for cloud computing services for USA Government. The cloud computing framework is neither an architecture nor an operating model. The framework is a functional view of the key capabilities required to enable cloud computing technology. It consists three major categories of cloud services:

- Cloud Service Delivery Capabilities - core capabilities required to deliver cloud services,
- Cloud Services - services delivered by the cloud,

- Cloud User Tools - tools or capabilities that enable users to procure, manage, and use the cloud services.

The horizontal functional areas represent the core of computing capabilities that enable different levels of cloud computing. The vertical functional areas illustrate the management and business capabilities needed to wrap-around the core components to enable business processes with cloud computing. For example, reporting and analytics offer the ability to perform key reporting and business intelligence analytics and therefore are not core cloud computing components. 
Table 2. Benefits in the practical example of CC technical framework (source: [18, p. 3])

\begin{tabular}{|c|c|c|}
\hline Type of benefits & Current environment & $\mathrm{CC}$ framework benefits \\
\hline \multirow{3}{*}{ Efficiency } & $\begin{array}{l}\text { - low asset utilization (i.e. servers utili- } \\
\text { zation }<30 \% \text { ) }\end{array}$ & $\begin{array}{l}\text { - improved asset utilization (i.e. servers utili- } \\
\text { zation increase to } 60-70 \% \text { ) }\end{array}$ \\
\hline & $\begin{array}{l}\text { - fragmented demand and duplicative } \\
\text { systems }\end{array}$ & $\begin{array}{l}\text { - aggregated demand and accelerated system } \\
\text { consolidation }\end{array}$ \\
\hline & - difficulty to manage systems & $\begin{array}{l}\text { - improved productivity in application de- } \\
\text { velopment, application management, net- } \\
\text { work, and end-user applications }\end{array}$ \\
\hline \multirow{2}{*}{ Agility } & $\begin{array}{l}\text { - years required to build data centers for } \\
\text { new services }\end{array}$ & - more responsive to urgent agency needs \\
\hline & $\begin{array}{l}\text { - months required to increase capacity } \\
\text { of existing services }\end{array}$ & $\begin{array}{l}\text { - instantaneous increases and reductions in } \\
\text { capacity }\end{array}$ \\
\hline \multirow{3}{*}{ Innovation } & - burdened by asset management & $\begin{array}{l}\text { - shift focus from asset ownership to service } \\
\text { management }\end{array}$ \\
\hline & $\begin{array}{l}\text { - decoupled from private sector innova- } \\
\text { tion engines }\end{array}$ & - tap into private sector innovation \\
\hline & - risk adverse culture & - encourages entrepreneurial culture \\
\hline
\end{tabular}

However, analytics offer significant business capabilities that can harness the power of the data that will reside within the cloud computing environment. For this project benefits shown in Table 2 were identified.

Among the most frequently mentioned benefits of $\mathrm{CC}$ technologies are [27, pp. 10-11]: scalability, easy implementation, skilled practitioners, frees up internal resources and quality of service. However, while mentioning undoubted advantages of cloud computing we cannot forget about its risks and faults. Gartner Institute $^{4}$ lists seven major threats [26]: data risk, regulatory compliance, data location, data segregation, recovery, investigative support and long-term viability. Many works are devoted for research of risk in implementations of CC framework, e.g. in works of Committee of Sponsoring Organizations of the Treadway Commission (COSO) are exchanged [13, pp. 4-5]: disruptive force, residing in the same risk ecosystem with other tenants of the cloud, lack of transparency, reliability and performance, vendor lock-in and lack of application portability or interoperability, security and compliance, high value of cyber attack, risk of data leakage, IT organizational changes and cloud service provider viability.

The above analysis shows that although the CC technology implementation is fraught with risk, and certainly is not the solution for everyone, it also creates an opportunity to increase efficiency and integrity in BI solutions. The conception of building a BI system in $\mathrm{CC}$ technology is shown in the next section.

\section{Cloud Business Intelligence - scenarios and strategies of system organization}

The diverse constructs introduced above lead to a framework that can help with identifying, combining, and evaluating potential services. This framework is visualized in Fig. 5.

The link to all possible variations is an umbrella of general provider and contract related issues. As in all outsourcing agreements, it needs to be thoroughly tested whether the provider is trustworthy. Besides, the contractual agreement has to pinpoint CC promises of high availability, data security, flexibility, scalability, and reliability in form of defined service level agreements.

The next building block in the framework is the actual composition of the service. This can be achieved by specifying the applied granularity on the tool layer (solution, component, or web-service) and by defining the subsumed BI services with the help of the dimensions component, business specificity, and life-cycle phase.

\footnotetext{
${ }^{4}$ Gartner Institute - is international research institute focused on analyses of IT market.
} 


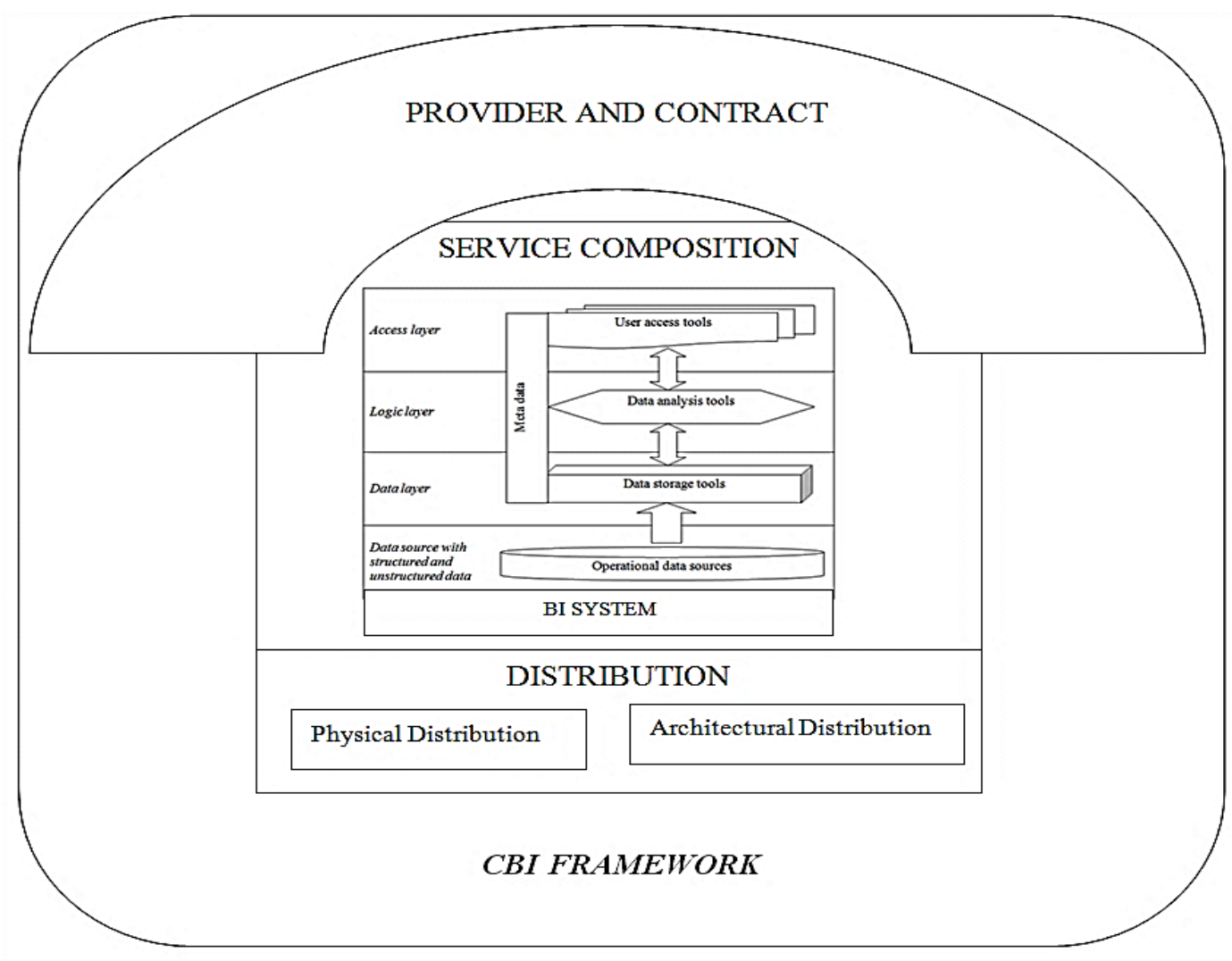

Figure 5. Cloud Business Intelligence framework (source: [3, p. 1535])

Next CC aspect is the distribution. In BI solutions it contains: physical distribution (with the options of confining the data storage locations to the premises of the provider, to keep the data in a network of business partners, or to freely distribute it on Internet level) and the architectural distribution (with the extremes of an end-to-end service provider on the one side and a best-of-breed solution composition that combines services of several providers on the other).

Finally intended benefits have to be reflected upon. This can refer to classical cost based outsourcing rationales or to harnessing the qualitative traits of $\mathrm{CC}$ approach (introducing flexibility, scalability, performance, or additional functionality). Besides, there might be informational benefits (through add-on data integration services from the provider) or even transformational effects (by adding new capabilities).

\subsection{Cloud Business Intelligence scenarios}

Starting from the above characteristics can suggest possible scenarios for implementing BI solutions in CC. The composition of the three basic elements: contract, service and distribution creates suitable scheme of (Fig. 6, [3, p. 1536]): add-on services scenario, tool replacement scenario, solution provision scenario, business network scenario, best-of-breed scenario, BI mashup scenario.

The add-on services scenario refers to the inclusion of selected functional blocks from CC into BI infrastructure. Examples are components for web information retrieval, web services for preprocessing qualitative data (e.g. with object or face recognition algorithms), data visualization components etc. By applying grid technologies on the provider side, even computation heavy features become affordable. The approach is relatively risk free because of its small scale.

In the tool replacement scenario CC idea is applied to complete software tool, e.g. web portal, data mart or OLAP tool. The tool replacement conforms to the SaaS idea with possible benefits being a more favorable cost structure, higher service levels and performance (e.g. when applied to complex analysis tools). Depending on the type of tool that is moved to $\mathrm{CC}$, this can become a critical cut into existing BI infrastructure with far reaching implications. Long term contracts with trusted vendors and a curbed data distribution seem suitable for this scenario. 


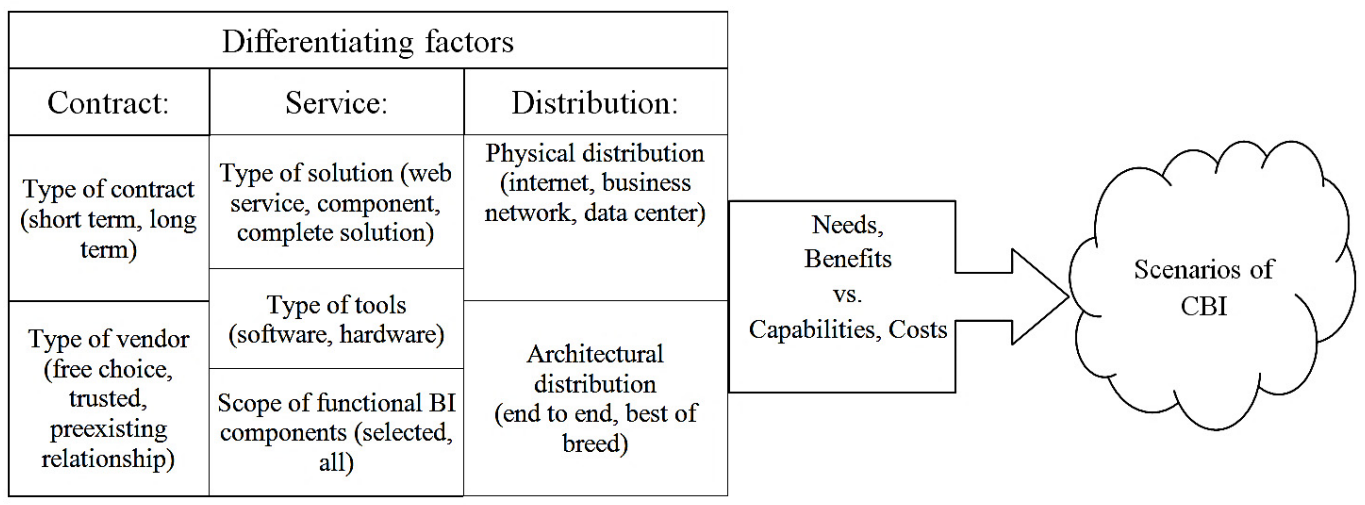

Figure 6. Cloud Business Intelligence scenarios (source: based on [3, p. 1536])

The solution provision scenario comes close to a classical ASP (Application Service Provider) agreement with the provider being responsible for the complete hardware and software of an isolated solution - end to end and across all layers. It has disadvantages as it possibly introduces a centrifugal force to an integrated BI infrastructure. It might however be suited for special purpose solutions that need to be set up fast, e.g. for a time-restricted data mining project or for piloting new types of applications.

The solution provider scenario comes from and acts within the confines of a business network. This might be a B2B marketplace, a franchise operation, a supply chain etc. The service provider is preferably a central and neutral partner in the network and provides solutions geared at the different members. $\mathrm{CC}$ aspect lies in the physical abstraction with the provider infrastructure being virtualized, i.e. by connecting the data center resources of the network members. This scenario also allows for information integration benefits.

The best-of-breed scenario is the idea of pushing the tool replacement scenario further up to the point where all components of the BI infrastructure are delivered by external providers. The result is a fully virtualized BI infrastructure that reaps all benefits of a best of breed resource allocation. Unfortunately this scenario is currently still hampered by the Cloud capabilities of some BI tools.

The BI mashup scenario assumes a freely composed BI solution sourced from a global Internet market space. Compared to the best-of breed scenario, it adds a finer granularity as well as a stronger focus on combinability and quick development (the development life cycle phase). The additional benefits primarily lie in its extreme agility.

\subsection{Cloud Business Intelligence integration strategy}

Integration of solution needs a very well defined strategy which provided CC capabilities. Success of the implementation depends on the existence of a service oriented strategy at the level of the organization, which would provide the necessary infrastructure for the $\mathrm{CC}$ implementation [16]. Based on recent research on integration of BI solution and transition it to CC ([23], [19]) it proposes the following strategy of implementation of solution in six stages (see Fig. 7).

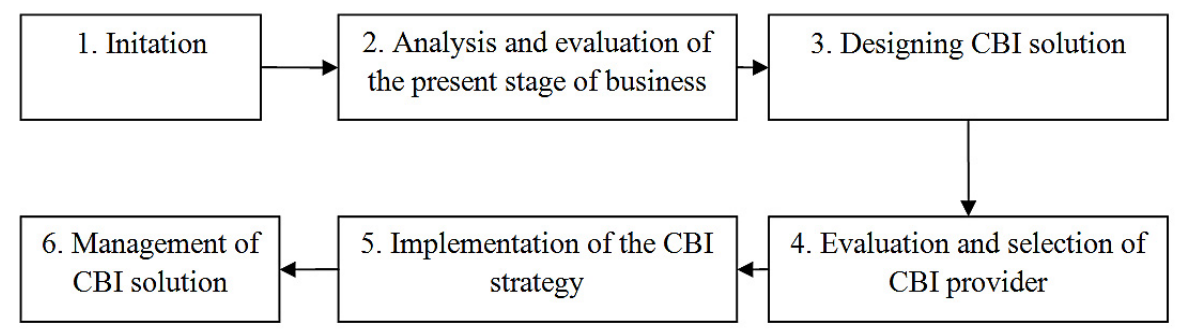

Figure 7. Stages of Cloud Business Intelligence integration strategy (source: [22, p. 44]) 


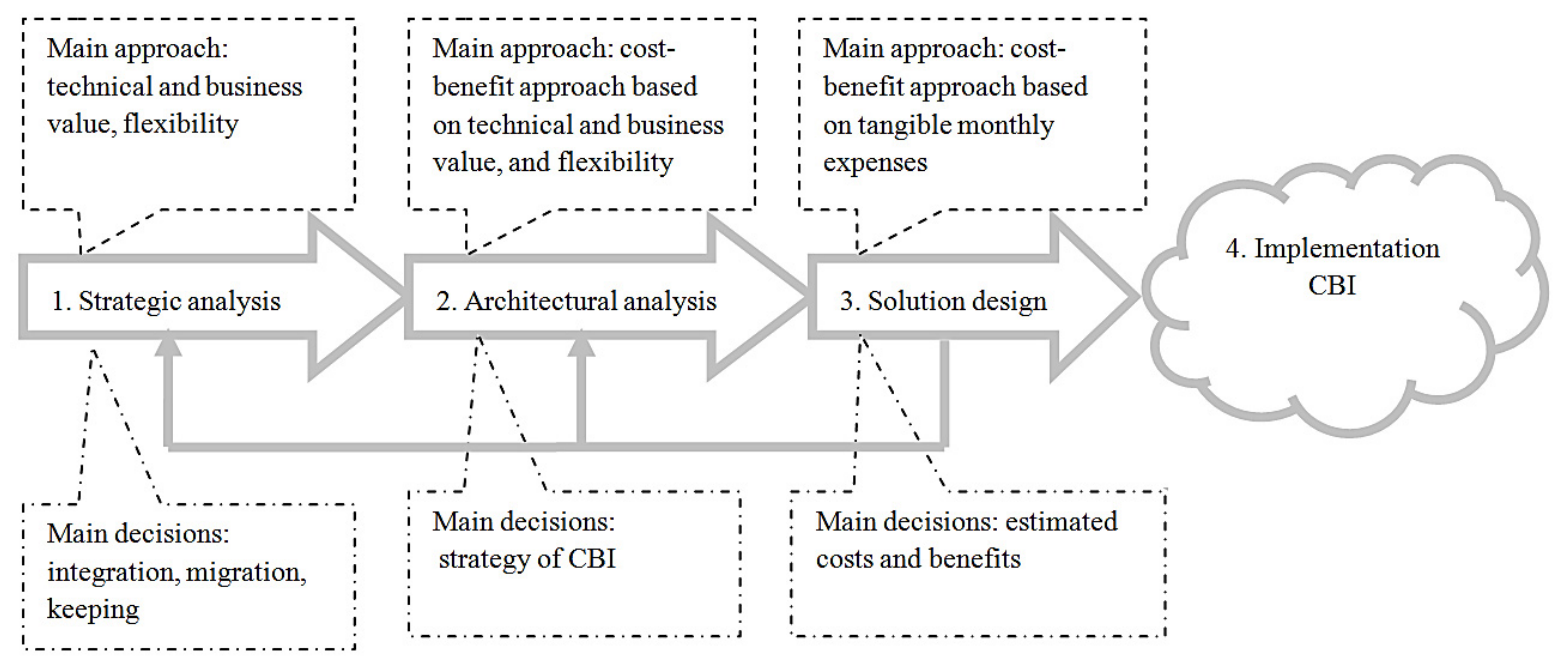

Figure 8. Decision model for choosing CBI solution (source: based on [22, p. 47])

Initiation stage includes identifying and setting the hierarchy of business objectives, assessing the budget needed to use solution, setting up the work team, the deadlines and the resources for implementation and maintenance. Also, within this stage the business users that will perform solution management must be identified and involved in the following stages. Strategy work team have to include IT personnel as well as business management. They will communicate with internal and external stakeholders concerning objectives, progress, costs and benefits for each cloud project.

For the success of strategy it is essential to identify resources used in the daily operations and in establishing the internal operation base. Also, at the level of the organization, the present needs and possible opportunities of solution have to be identified. Therefore, the present stage of business has to be analyzed and evaluated both from an internal and an external perspective of the business, putting the stress on the culture and value of business, on important business processes and business infrastructure. Evaluation of business infrastructure involves, among other things, analysis of management and security of applications, data storage, finding and classifying data.

Designing of solution may be achieved through the following steps:

- mapping BI requirements and IT culture according to one of CC models - the key for the success of strategy is obtaining the correct combination between the cloud and internal development for taking advantage of both solutions. Transition to the cloud may be achieved gradually, and the software provision models will coexist for a period of time,

- identification and evaluation of the different plans of verification of the benefits of solution - for the evaluation of different plans, the types of criteria determining the opportunity of solution in a specific situation must be analyzed, such as: level of personalization of data sources; priority of BI solution on the list of internal IT projects; considerations regarding security, risks, regulatory and privacy issues; development of organization and applications,

- identification of the main providers that meet the operational, technical and business requirements - identification may be achieved based on information from search engines, consulting firms, and from other sources. Selection of candidate platforms may be made between the traditional BI providers that have adapted their offer to the cloud or/and the new providers specialized in BI products in cloud.

The evaluation of solutions/providers has to be done based on the most recent sources (provider, consulting firms, the newest articles), the rest of the sources of information representing the grounds for obtaining a global image of the market of BI in CC. Within this stage takes place the analysis and testing of solutions, the selection of candidate solutions, identification of major changes and obtaining insurance from the selected providers. The model of decision for choosing the solution combines strategic factors and techniques with cost-benefit analyses for decisions of migration, versus integration or keeping in house (see Fig. 8). 
Table 3. Restrictions BI technology on SME sector vs. CBI system conception (source: own research)

\begin{tabular}{|l|l|}
\hline \multicolumn{1}{|c|}{ Restrictions BI technology in SME sector } & \multicolumn{1}{c|}{ CBI solution } \\
\hline $\begin{array}{l}\text { lack of knowledge in the area of possibilities effective- } \\
\text { ly support management decisions }\end{array}$ & $\begin{array}{l}\text { supplied as the complete solution and does not require } \\
\text { knowledge of advanced information technology }\end{array}$ \\
\hline $\begin{array}{l}\text { limited knowledge of modern methods and models } \\
\text { of business management }\end{array}$ & $\begin{array}{l}\text { based its concept of architecture and structure of the data } \\
\text { model on the predefined model of key competitiveness fac- } \\
\text { tors, dedicated to a specific group of enterprises }\end{array}$ \\
\hline $\begin{array}{l}\text { inability to self implementation and maintenance of BI } \\
\text { system }\end{array}$ & $\begin{array}{l}\text { implemented and delivered as a service (e.g. outsourcing, } \\
\text { cloud computing) }\end{array}$ \\
\hline $\begin{array}{l}\text { limited resources for budgeting IT projects } \\
\text { limited and insufficient number of collected source } \\
\text { data }\end{array}$ & $\begin{array}{l}\text { implemented, maintained and funded as a product shared } \\
\text { by a group of enterprises, and not as individual solution }\end{array}$ \\
\hline
\end{tabular}

The major decisions, in this model, are: strategic analyses for grounding decisions of migration/ integration/ keeping based on business factors, architectural analyses based on intangible cost-benefit analyses of strategic decisions and the selected solution based on the analyses made.

Based on the final offer of the provider, the team will measure the impact of the selected solution on the organization, assessing costs and benefits in order to determine the opportunity of integration and the key elements under negotiation. Finally, based on the offer and the model of contract, the contractual elements are negotiated: price, service conditions, payment, obligations of the parties, etc., and the contract is closed.

Implementation of solution may be achieved in iterative stages, through continuous transmission of data, services and processes toward the cloud, with possible returns from the cloud to operations hosted internally. This is achieved through continuous evaluations of the benefits of cloud technologies. Also, implementation involves setting a flexible program of risk management (to cope with IT risks that are increasing continually), testing the solution's performance and the management of implementation.

Utilization of solution involves changes in the manipulation of processes, such as data processing, development, receipt of information, means of storage, archiving and saving data, etc. Migration of critical applications and infrastructure to $\mathrm{CC}$ and maintaining the business activity involves important human re- sources for the management of sensitive data and of applications during migration. At the end of the solution's implementation takes place the training of users in operating the new systems.

At the level of the management stage must be present a management model that should include policies on security, the management of applications and infrastructure, risk management and continuous evaluation of solution. An efficient management is essential for any quality management program. It supports proactive ensuring of quality by measuring and improving processes, procedures and services. Besides the typical components of BI solution in monitoring solution must be taken into account the specific elements of CC environment. Among them, the most important are: monitoring URLs, monitoring system resources, monitoring $\log$ files, event management, multi-client capabilities, evaluation of contracts with providers.

The process of selecting strategy is iterative and is based on the results of the technical and economical analyses. Every iteration of the presented cycle identifies and eliminates the platforms of solutions that are unacceptable or unavailable, configurations that are too expensive or solutions with an unacceptable level of security. The number of iterations depends on the number of available candidate solutions. An attempt to select and propose concrete the solutions for a SMEs group will be shown in the next section. 


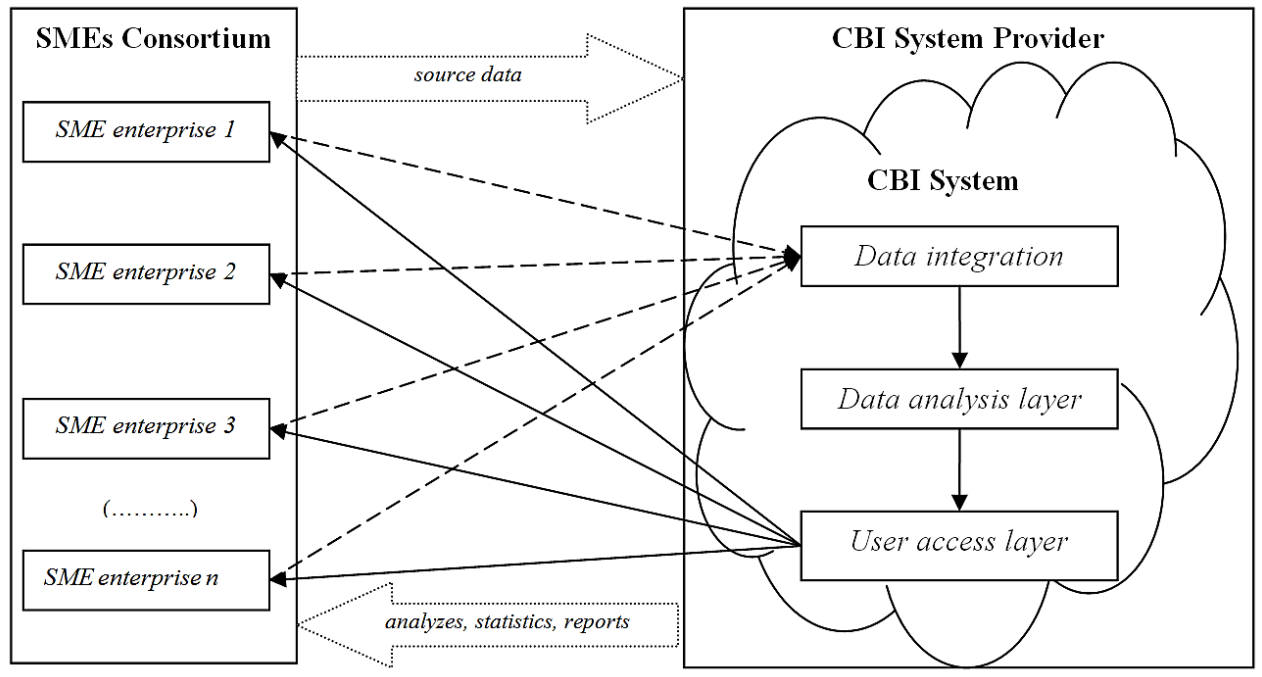

Figure 9. The model of CBI system for SMEs Consortium (source: own work)

\section{Cloud Business Intelligence for SMEs - proposition of using}

Proposed concept of CBI is based on the assumption that SME receives ready to use product, which actively supports the development of its competitive strategy. This has a direct impact on the scope of the functionality of BI tool, but is necessary due to the low awareness of management employees and thus also to the lack of skills to use computer applications supporting the decision-making process. This problem does not only concern the SME sector, but all uses of advanced analytical systems which after implementation are not properly operated and consequently does not bring expected economic and performance outcomes. Proposed BI solution has predefined modules equipped with complete set of analyzes and reports (dedicated to specific industry or business) and data warehouse integrates data collected from group of enterprises (instead from single one).

With the adoption of a common solution for the group of comparable and mutually competing enterprises becomes available the functionality, which has hitherto was not known. It is a possibility of realization of a benchmarking analysis in the group of competing firms. Based on these analysis is possible to determine their competitive position and benefit from the experience of the group leaders during define the individual strategy for competitiveness. Specific reference to the restrictions in relation to the solutions proposed in system presents Table 3 .
The model of CBI system is presented at Fig. 9.

The aim of CBI implementation is to support decisionmaking process in managing of competitiveness development. Use of CBI for this purpose will result in:

- the ability determine the current enterprise position of the competitive market,

- the adjustment of competitiveness development strategy to this competitiveness position which the enterprise intends to achieve in the future.

This is made possible by the fact that source data into the system are delivered by the group of users, and not by a single enterprise. This concept is consistent with the approach proposed by analysts of Gartner Institute [33], who at Gartner BI Summit Conference in May 2011 proposed the output with BI system outside the enterprise by using not only internal but also external data sources. The postulate was seen as useful, but very difficult to pursue. Proposed solution demonstrates how it can be achieve in the practice

Group of CBI users periodically delivers their source data over the lifetime of the system. It is a prerequisite to ensure its actuality and usefulness. The source data are integrated in a common repository of data, processed analytically and made available to users in the form of ready-made analytical results, statistical summaries and reports.

Data model (data integration layer at Fig. 9) and analytical layer of CBI system are dedicated exactly to the needs of its users. 
They are based on the competitive model, selecting key competitiveness factors and designating the current competitive position of the enterprise in the group. In addition CBI system is delivered as a service, so the management of it is on the provider side and not the users. There are many different variants of outsourcing services in BI systems [2, s. 1164]:

- reporting service - outsourcing of tools to build analytical reports via the internet based solely on local data of the user,

- OLAP service - outsourcing of multi-dimensional analytic structure built on the basis of market data, which can be expanded on user's own data and integrated with its analytical system,

- data mining and visualization of data service the client uses an external service of professionals in the implementation and the presentation of results analyzes based on the resources of own collected data,

- data warehouse and ETL service - supplying data into the data warehouse and maintaining its resources is done exclusively by the equipment provider.

It is clear, that these types of outsourcing services can be combined, for example by taking advantage of data warehouse and ETL service with data mining and data visualization service. The chosen variant of CBI system type will have then a direct impact on its architecture. Right choice the variant of CBI system implementation is determined by the answers to three basic questions:

- what elements of the CBI system the enterprise is able to maintain independently, and which must be transferred to outsource?

- what resources of data are available for analysis (in terms of their quantity, quality and range of information ) and what is their level of confidentiality?

- how many the enterprise is able to pay for the implementation and the maintenance of CBI system?

The answer to these questions allows the selection of a package of services which must be done outside and those that can be implemented locally. It should carefully consider rights and responsibilities of the provider and the recipient in the range of organization and management of CBI architecture, taking into account the need to ensure a dynamic development of this architecture and available system functionalities. Adjustment of the project from one side to the needs and on the other side to the capacity of the enterprise is simply defining the set of system functionality in the case of using outsourcing or cloud computing services. That set of functionality ensures the implementation of user needs and is acceptable for the enterprise taking into account the extent of obligations arising from the need to ensure system efficiency and costs (taking into account amounts associated with maintenance of the system such as monthly fee).

In proposed concept the stage before the implementation of CBI system project is the construction of reference model of key competitiveness factors. Main goal of the model is determining the competitive position occupied by the enterprise in analyzed group. The model allows both: to conduct internal analysis of the competitiveness of the enterprise, and to compare its situation with respect to the competitive environment (which are co-users of CBI system). Obtained results provide managers with the knowledge about the importance and the impact of identified key competitiveness factors on the competitive position, which then is reflecting in developed strategy and results in increase the efficiency of competitiveness development management. Applying reference model of key competitiveness factors as the basis for CBI system project, guarantees its suitability and usability for the enterprise in defined range of analytical and decision-making uses.

Using CBI system always increases the awareness of managers in possibilities of using IT solutions in decision-making process. Analytical and reporting needs of users are changing and usually expanding during the work with the system. If the system is supplied as a service its development is possible and available at any time of user requests. Expected changes in services are provided by the supplier and only burden for the user is the change of monthly fee. Presented CBI system concept, offered as a service with predefined analytical module and database structure adapted to this module, becomes economically, technically and organizationally available for SMEs.

Measurable and immeasurable benefits of using that system are described in Tab. 4. The implementation and effective use of CBI system will result in time savings, rationalization of costs and the optimization of management efficiency. Proposed system architecture also allows the enrichment of own management experience by experiences of competing enterprises in the common market, according to good practices and ethical code of benchmarking. 
Table 4. Expected effects of the implementation of CBI system dedicated to SMEs (source: own research)

\begin{tabular}{|l|l|l|}
\hline \multicolumn{1}{|c|}{ Feature of CBI system } & \multicolumn{1}{|c|}{ Measurable effects } & \multicolumn{1}{|c|}{ Immeasurable effects } \\
\hline $\begin{array}{l}\text { analysis of competitive posi- } \\
\text { tion of the enterprise }\end{array}$ & $\begin{array}{l}\text { maximization of the profit, rationalization } \\
\text { of costs }\end{array}$ & $\begin{array}{l}\text { supporting of setting goals and direc- } \\
\text { tions of a development of competitive } \\
\text { strategy }\end{array}$ \\
\hline $\begin{array}{l}\text { benchmarking results be- } \\
\text { tween co-users CBI system } \\
\text { of costs }\end{array}$ & maximization of the profit, rationalization & $\begin{array}{l}\text { determination of competitive strategy } \\
\text { targeted by experiences co-users of } \\
\text { CBI }\end{array}$ \\
\hline $\begin{array}{l}\text { analyzes and reports } \\
\text { pudget preparation }\end{array}$ & $\begin{array}{l}\text { reduction of uncertainty degree in man- } \\
\text { agement decision-making process } \\
\text { opment of enterprise competitiveness }\end{array}$ & $\begin{array}{l}\text { reduction of operational risk in man- } \\
\text { agement decisions making process }\end{array}$ \\
\hline $\begin{array}{l}\text { analytical data repository, } \\
\text { data warehouse }\end{array}$ & $\begin{array}{l}\text { reduce the time to access to management } \\
\text { information }\end{array}$ & $\begin{array}{l}\text { increased availability of analytical data } \\
\text { for wider range of users in any place } \\
\text { and any time }\end{array}$ \\
\hline $\begin{array}{l}\text { multidimensional data pro- } \\
\text { cessing tools }\end{array}$ & $\begin{array}{l}\text { reduce the time to prepare and modify que- } \\
\text { ries and analysis }\end{array}$ & $\begin{array}{l}\text { increased availability of analysis for } \\
\text { wider range of users in any place and } \\
\text { any time }\end{array}$ \\
\hline $\begin{array}{l}\text { visualization tools, presenta- } \\
\text { tion and distribution of in- } \\
\text { formation }\end{array}$ & $\begin{array}{l}\text { reduce the time to prepare, modification and } \\
\text { distribution of reports }\end{array}$ & $\begin{array}{l}\text { increased availability of management } \\
\text { information for wider range of users in } \\
\text { any place and any time }\end{array}$ \\
\hline $\begin{array}{l}\text { ETL tools } \\
\text { ancrease data quality also in transactional } \\
\text { systems }\end{array}$ & $\begin{array}{l}\text { data standardization in the whole of the } \\
\text { enterprise and of co-users CBI system }\end{array}$ \\
\hline
\end{tabular}

The verification of usefulness proposed solution was based on the research experiment, which involved 10 of initial group of 150 dental clinics (covered by survey research $^{5}$, [28]). Data collected from these clinics were used to build DBI system (Dedicated Business Intelligence). The purpose of using system was to determine competitive position of each clinic in the group. This was made possible by creating reference model of key competitiveness factors, which in three identified areas of measurable effects (E1 - modernity and quality of medical services, E2 - the ability to meet the needs of patients, E3 - results of sales) on the basis of calculated values of key competitiveness factors (C1- technological level, C2 - the quality of services, C3 - timeliness of service delivery, C4 - lasting relationships with customers, C5 - sales, C6 - costs and expenses, C7 - the utilization of fixed assets, C8 the staff productivity) defined value of the competitive position CP for each enterprise in analyzed group. Then benchmarking of obtained results allowed for matching strategy of competitive development for this competitive position, which the clinic intends to take in this group in the future [28].

Results obtained during the experiment confirmed the usefulness of the proposed concept of DBI solution.

\footnotetext{
5 Scientific work financed from budget funds for science in 2009-2011 as a research project No. 0078/B/H03/2009/37.
}

DBI system enhanced by reference model of key competitiveness factors was more understandable, friendly and helpful to users than IT solution equipped only with analytical and reporting tools. As a proof of costeffectiveness and effectiveness of DBI implementation it was carried out analysis, presenting below.

It is assumed that a properly implemented and effectively used BI system should be paid after 3 years of use. Accepting this argument and based on the results of research conducted by 180 Systems [6] and Pentaho [21] it can be concluded that the costs of implementation and maintenance of $\mathrm{BI}$ within the first three years of use are at a level of $30000-100$ $000 \$$ in small companies and $30000-400000 \$$ in medium-sized companies. Referring to the cost of the financial performance of the SME sector in Poland can be said that the implementation of the BI system and keep it in the first year of life is a burden of $3.5 \%-25.5 \%$ of the annual earnings of a small company and $2.8 \%-30 \%$ average annual earnings the middle company.

During the 3 years, which is the assumed period of return on investment in $\mathrm{BI}$, this load is 3,4\% -12\% 3 year earnings of a small company and 1\% $-13,5 \% 3-$ year earnings middle company. 
Table 5. The participation of DBI system cost in financial results of the group of 12 small enterprises (summary about 25 users)

(source: own research)

\begin{tabular}{|l|l|c|c|}
\hline \multirow{2}{*}{ Software vendor } & & \multicolumn{1}{c|}{ System cost / financial result [\%] } \\
\cline { 2 - 4 } & \multicolumn{1}{|c|}{ Solution name } & $\begin{array}{c}\text { in 1st year of the } \\
\text { system lifetime }\end{array}$ & $\begin{array}{c}\text { within 3 years of the } \\
\text { system lifetime }\end{array}$ \\
\hline Microsoft & SQL Server 2008 R2 Enterprise Edition & 0,86 & 0,29 \\
\hline QlikTech & QlikView & 1,36 & 0,69 \\
\hline $\begin{array}{l}\text { Pentaho (open } \\
\text { Source solution) }\end{array}$ & Pentaho Business Intelligence Gold Edition & 0,86 & 0,86 \\
\hline SAP & SAP BusinessObjects Edge Professional Edition & 4,54 & 2,05 \\
\hline MicroStrategy & MicroStrategy 9 & 6,28 & 2,85 \\
\hline IBM & Cognos 8 Business Intelligence & 6,72 & 3,16 \\
\hline Oracle & $\begin{array}{l}\text { Oracle Business Intelligence Suite Enterprise } \\
\text { Edition Plus }\end{array}$ & 9,17 & 4,16 \\
\hline
\end{tabular}

Especially the upper limits of these ranges are a barrier for capabilities of implementing BI in SMEs By adopting the proposed DBI solution, in which users of the system is a group of 12 small enterprises SMEs and system architecture is planned for about 25 users, load in the first year of the system is less than $10 \%$ of the earnings of each company, and in 3-year period below 3,5\% of 3-year earnings of each of them (see Table 5).
Thus, for each of the project implementation, knowing the estimated costs as defined by the software vendor and the service provider, you can determine the optimal size of the group users DBI system, which will reduce costs and increase the efficiency of its implementation.

Considering the effects of the use DBI solution in the research group it can be note the change of the results after using prepared analyzes and reports in 2008-2009 and their impact on the results of 2010 (see Table 6).

Table 6. DBI system efficiency in 2010

(source: own research)

\begin{tabular}{|c|c|c|c|c|c|}
\hline \multicolumn{2}{|c|}{ The period of analysis } & $\begin{array}{l}\text { Number } \\
\text { of patients }\end{array}$ & $\begin{array}{c}\text { The gross } \\
\text { of sales value }\end{array}$ & $\begin{array}{l}\text { The profit } \\
\text { value }\end{array}$ & $\begin{array}{l}\text { Number } \\
\text { of patient }\end{array}$ \\
\hline \multirow{2}{*}{ 2008-2009 } & $\begin{array}{c}\text { on average within } 2 \text { months } \\
\text { [thousand. PLN] }\end{array}$ & 4714 & 319,00 & 28,00 & 2011 \\
\hline & on one patient visit [PLN] & & 158,64 & 13,73 & \\
\hline \multirow{2}{*}{2010} & $\begin{array}{c}\text { on average within } 2 \text { months } \\
\text { [thousand. PLN] }\end{array}$ & 18742 & 603,00 & 97,00 & 3760 \\
\hline & on one patient visit [PLN] & & 160,28 & 25,68 & \\
\hline \multirow{2}{*}{$\begin{array}{l}\text { The difference: } \\
\text { 2010-(2008/2009) }\end{array}$} & $\begin{array}{c}\text { on average within } 2 \text { months } \\
\text { [thousand. PLN] }\end{array}$ & 14028 & 284,00 & 69,00 & 1749 \\
\hline & on one patient visit [PLN] & & 1,64 & 11,95 & \\
\hline
\end{tabular}


Table 7. ROI for the implementation of DBI by a single vs. a group of 10 clinics (source: own research)

\begin{tabular}{|c|c|c|c|c|c|}
\hline $\begin{array}{l}\text { Software } \\
\text { vendor }\end{array}$ & Solution name & $\begin{array}{l}\text { ROI (1year) } \\
\text { for single } \\
\text { clinic }\end{array}$ & $\begin{array}{l}\text { ROI (1 year) } \\
\text { for a group } \\
\text { of } 10 \text { clinics }\end{array}$ & $\begin{array}{l}\text { ROI ( } 3 \text { years) } \\
\text { for single clinic }\end{array}$ & $\begin{array}{l}\text { ROI ( } 3 \text { years) } \\
\text { for a group } \\
\text { of } 10 \text { clinics }\end{array}$ \\
\hline Microsoft & $\begin{array}{l}\text { SQL Server } 2008 \text { R2 } \\
\text { Enterprise Edition }\end{array}$ & $35,64 \%$ & $1256,38 \%$ & $306,91 \%$ & $3969,13 \%$ \\
\hline QlikTech & QlikView & $-14,49 \%$ & $755,11 \%$ & $68,58 \%$ & $1585,78 \%$ \\
\hline $\begin{array}{l}\text { Pentaho (open } \\
\text { source solution) }\end{array}$ & $\begin{array}{l}\text { Pentaho Business Intelli- } \\
\text { gence Gold Edition }\end{array}$ & $35,64 \%$ & $1256,38 \%$ & $35,64 \%$ & $1256,38 \%$ \\
\hline SAP & $\begin{array}{l}\text { SAP BusinessObjects } \\
\text { Edge Professional Edi- } \\
\text { tion }\end{array}$ & $-74,46 \%$ & $155,42 \%$ & $-43,54 \%$ & $464,62 \%$ \\
\hline MicroStrategy & MicroStrategy 9 & $-81,53 \%$ & $84,67 \%$ & $-59,31 \%$ & $306,91 \%$ \\
\hline IBM & $\begin{array}{l}\text { Cognos } 8 \text { Business Intel- } \\
\text { ligence }\end{array}$ & $-82,75 \%$ & $72,52 \%$ & $-63,24 \%$ & $267,62 \%$ \\
\hline Oracle & $\begin{array}{l}\text { Oracle Business Intelli- } \\
\text { gence Suite Enterprise } \\
\text { Edition Plus }\end{array}$ & $-87,35 \%$ & $26,48 \%$ & $-72,10 \%$ & $178,97 \%$ \\
\hline
\end{tabular}

The 2-monthly periods of 2010 compared to the years 2008-2009 the gross sales value grew by an average of 284 thousand. PLN, and the value of profits earned in that period by 69 thousand. PLN. Assuming that about $50 \%$ of this profit is a result of the use of prepared analyzes and reports in the management process and that this trend will be permanent, it becomes possible to calculate the rate of return on investment ROI in one-year and three-year periods (see Table 7).

Table 7 shows that acting alone clinics could implement only the cheapest solutions - Microsoft, QlikTech or Pentaho. However as a group of 10 clinics, using a common system of DBI, are able to benefit from the offer of any vendor, even with the most expensive solution at the market. In this situation the determinant of used technology are not limited financial resources, but the actual analytical and information needs of an enterprise. This confirms the validity of the concept of group system implementation for the SME sector.

\section{Summary}

On the basis of researches results, shown in the paper, it can be stated that nowadays SMEs in Polish market have very small extent to use of IT tools to support managerial decision-making process. However, as practice shows and conducted BI market researches, use of IT tools can significantly increase the quality, and reduce the risk and costs of such decisions. As has been shown the Cloud Computing creates new opportunities for implementation of the Business Intelligence systems in these business sectors and organizations, for which up to now it was not feasible for many different reasons.

The implementation of typical BI solutions in the form of the system (as a whole realized and maintained by the enterprise) in most cases is for SMEs technically, organizationally and economically impossible. It is also very difficult for network and virtual organizations, consisting of multiple cooperating objects. Additional constraint is the low awareness of the managers in the SME sector in the scope of information technology and advanced methods of data analysis and insufficient number of collected data. Therefore, the proposed solution is based on following assumptions:

- CBI system is offered as a service for not only one but for whole group of SME users,

- all users of CBI supply their data into the system, thus increasing informational and analytical system strength,

- the construction of CBI system is based on predefined components, in which the key role plays the reference model of competitiveness factors, dedicated to specific group of SMEs,

- the use of CBI system is intuitive, focused on the use of ready-made packages of analysis and reports scenarios. 
The proposed concept of CBI system can efficiently support the development of strategies shaping competitiveness in SMEs. Therefore, it is the prospect of develop BI technology and the possibility of its wider use in enterprises of all business sectors.

Moreover, this kind of solution is not only reserved for SMEs. It can be a great opportunity for both network and virtual organizations that nowadays are seen as flexible and cost efficient. Despite their structure and physical location (a virtual organization might not have even have a permanent office), they still require an intensive knowledge sharing and exchange. Unfortunately, in this environment, a traditional BI solution could be highly difficult to introduce. A BI system in $\mathrm{CC}$ technology opens new chances that may result in profits presented in the second section. As the technology is fast-moving those organizations benefit from the new possibilities on the market-place. Smirnov et al. [29] mention some of them in such a collaboration environment:

- decentralization: business services can be completely decentralized and distributed over the Internet and accessed by a wide variety of communications devices,

- dynamic interoperability: new business partnerships can be constructed dynamically and probably even automatically,

- flexibility: a highly-dynamic enterprise consortium have greater possibilities to use new market opportunities.

To sum up, BI system in CC technology opens up new perspectives for: SMEs, network and virtual organizations and many others, who need effective support when making management decisions, and are not in a position themselves implement and maintain BI system.

\section{References}

[1] Armbrust M., Fox A., Griffith R., Katz R. - Above the Clouds: A Berkeley View of Cloud Computing. University of California, UC Berkeley Reliable Adaptive Distributed Systems Laboratory, 2009.

[2] Baars H., Horakh T.A., Kemper H. - Business Intelligence Outsourcing a Framework. European Conference on Information Systems. St. Gallen, Switzerland, 2007, pp. 1155-1166.

[3] Baars H., Kemper H. - Business Intelligence in the Cloud? PACIS 2010 Proceedings. Paper 145, 2010, pp. 1528-1539.
[4] Badger L., Grance T., Patt-Corner R., Voas J. DRAFT Cloud Computing Synopsis and Recommendations. National Institute of Standards and Technology (NIST), 2011.

[5] Baig A. - White paper: A Cloud Guide for HPCTop Drivers, Barriers, Use Cases, and Vendor Requirements for Private and Public HPC Cloud Computing. May 2009. Retrieved June 18, 2009, from univaud.com/about/resources/files/wp-cloudguide-hpc.pdf.

[6] Burns M. - BI/CPM Survey 2009. Using Technology to Improve the Way You Do Business. CA Magazine, Canada, 2009.

[7] Chan T. - Full Interview: AT\&T's Joe Weinman. Green Telecom Live, March 16, 2009. Retrieved May 20, 2009, from

greentelecomlive.com/2009/03/16/full-interviewatt's-joe-weinman/

[8] Chunxu J.H., Li W.J. Research on EDA based Right-Time Business Intelligence System. Information Management and Engineering (ICIME), The 2nd IEEE International Conference on 2010, Chengdu, 2010, pp. 476 - 479.

[9] Cui Z., Damiani E., Leida M. - Benefits of Ontologies in Real Time Data Access. Digital Ecosystems and Technologies Conference, DEST'07, 2007, pp. 392-397.

[10] DiS - Rynek BI w Polsce 2005-2012. Monitor IT, Vol. 14, No. 2 (321), 2010.

[11] Hongfeng X., Liya Y. - Research Standardization for Business Intelligence Systems Integration based on SaaS. Networking and Digital Society. ICNDS '09. International Conference on 2009, Vol. 2, Guiyang, Guizhou, 2009, pp. 242-246.

[12] Horvitz P. - An Introduction to Cloud Computing in the Federal Public Sector. Apptis CTO, 2010. http://www.apptis.com/solsec/solutions/cloud/appti s\%20-\%200826-2_introtocloudcomputing_whitepaper.pdf.

[13] Horwath C.- Enterprise Risk Management for Cloud Computing. The Committee of Sponsoring Organizations of the Treadway Commission, 2012. http://www.coso.org/documents/ Cloud\%20Computing\%20Thought\%20Paper.pdf.

[14] IBM - What is BI?. Retrieved February 11, 2012, http://www1.ibm.com/servers/solutions/bi/what.ht $\mathrm{ml}$.

[15] Jaeger P., Lin J., Grimes J., Simmons S. - Where is the Cloud? Geography, Economics, Environment, and Jurisdiction in Cloud Computing. First Monday, 14(5), May 4, 2009.

[16] Kavis M. - A Move to Cloud Computing Should Involve SOA and BPM, TechTarget. CIO News, 2009,

http://searchcio.techtarget.com/news/column/0,294 698,sid182_gci1355577,00.html 
[17] Kemper H.G., Baars H. - Business Intelligence und Competitive Intelligence - IT-basierte Managementunterstützung und markt-/wettbewerbsorientierte Anwendungen [in] Business \& Competitive Intelligence (eds. H.G. Kemper, H. Heilmann, H. Baars), 2006, pp. 7-20.

[18] Kundra V. - Federal Cloud Computing Strategy. The White House, Washington, 2011, http://www.cio.gov/documents/federal-cloudcomputing-strategy.pdf

[19] Li H., Sedayao J., Hahn-Steichen J., Jimison E., Spence C., Chahal S. - Developing an Enterprise Cloud Computing Strategy. White paper, Intel Information Technology, 2009,

http://www.intel.com/content/www/us/en/cloudcomputing/software-as-a-service--saas-/intel-itdeveloping-cloud-computing-strategy-paper.html

[20] Liautaud B., Hammond M. - E-Business Intelligence. Turning Information into Knowledge into Profit. McGraw-Hill, New York, 2002.

[21] Madsen M. - Lowering the Cost of Business Intelligence With Open Source. Third Nature, Rogue River, USA, 2010.

[22] Mircea M., Ghilic-Micu B., Stoica M. - Combining Business Intelligence with Cloud Computing to Delivery Agility in Actual Economy. Journal of Economic Computation and Economic Cybernetics Studies, No. 1, 2011, pp. 39-54.

[23] Mircea M. - Strategy for Selecting a Business Intelligence Solution. Informatica Economică, No. 1(45), Published by INFOREC Association, 2008, pp. 103-109.

[24] Moore A. - Cloud Computing - Definitions, Concepts and Architecture. Internet, 2012, http://blog.spinxwebdesignatlanta.com/cloudcomputing-definitions-concepts-and-architecture (read 22.08.2012).

[25] Moss L.T., Alert S. - Business Intelligence RoadMap - the Complete Project Lifecycle for Decision Support Applications. Addison-Wesley, 2003.
[26] Plummer D.C., Cearley D.W., Smith D.M. - Cloud Computing Confusion Leads to Opportunity. Gartner Research Report, No. G00159034, 2008.

[27] Pyke J. - Enterprise Cloud Computing. An introductory guide for CIOs, 2012,

http://cloudbestpractices.files.wordpress.com /2012 /06/ enterprisecloud.pdf

[28] Rostek K. - The Reference Model of CompeteTiveness Factors for SME Medical Sector. Economic Modelling 29 (2012), pp. 2039-2048.

[29] Smirnov A., Pashkin M., Chilov N., Levashova T., Krizhanovsky A. - High-Level Business Intelligence Service in Networked Organizations [in] Abstracts of e-Business Research Forum eBRF 2003. Tampere, 2003, pp. 37-39.

[30] Turban E., Aronson J.E., Liang T-P., Sharda R. Decision Support and Business Intelligence Systems (8th ed.). New Jersey: Pearson Education, 2007.

[31] Turban E., Sharda R., Delen D. - Decision Support and Business Intelligence Systems (9th ed.). New Jersey. Pearson Education, 2011.

[32] Venkatadri M., Hanumat G.S., Manjunath G. A Novel Business Intelligence System Framework. Universal Journal of Computer Science and Engineering Technology, Vol. 1, No. 2, 2010, pp. 112116.

[33] Vijayan J. - BI Must Become Part of Broad IT Strategy. Computerworld, Los Angeles, 2011. http://www.computerworld.com/s/article/9216450/ BI_must_become_part_of_broad_IT_strategy (read on 22.08.2012).

[34] Xu L.Z. - Business Intelligence and Its Application and Design in Electric Power Marketing. Power Demand Side Management, Vol. 8, 2006, pp. 3032.

[35] Yu C.H., Pan H.P. - Business Intelligence and Its Key Technology. Application Research of Computers, Vol.19, 2002, pp. 14-16.

[36] Żółcińska W. - Czego polskie firmy oczekuja od BI? CIO Magazyn Dyrektorów IT, International Data Group Poland, No. 07/2009, Warszawa 2009. 